\title{
Cross ectopic multicystic dysplastic kidney with ureterocele in nonectopic site
}

\author{
Adnan Narcı, MD; ${ }^{*}$ Mevlit Korkmaz, MD; ${ }^{*}$ Muhittin Karakuş, MD; Tolga Altuğ Sen, MD, Îlhamı Surer, MD;+ \\ Salih Çetinkurşun, $M D^{*}$
}

\begin{abstract}
Crossed renal ectopy (CRE) is the second most common fusion anomaly of the kidney, with an incidence of 1 in 7000 autopsies; it comes in second after horseshoe kidney. Crossed renal ectopy is associated with an ectopic ureter and generally an ectopic kidney fused with a normal kidney. A 7-month-old boy who had left-toright crossed non-fused renal ectopy and multicystic renal dysplasia with ureterocele in nonectopic kidney was reported in English language literature. In this article, we present the first case of CRE where surgical intervention has been performed.
\end{abstract}

Can Urol Assoc J 2010;4(3):E61-E63

\section{Introduction}

Crossed renal ectopy (CRE) is the second most common fusion anomaly of the kidney, with an incidence of 1 in 7000 autopsies; it comes in second after horseshoe kidney. ${ }^{1}$ Crossed renal ectopy is relatively common in males; in most of these cases, the left kidney is crossed to the right. There is great variability in the aberrant vascular supply, which can arise from either side of the lower aorta or from the common or external iliac arteries. ${ }^{2}$ Although most of the CRE cases are asymptomatic and incidentally diagnosed, early diagnosis may prevent possible urinary infections, obstructions and malignancies. ${ }^{3,4}$ We present a left-to-right crossed multicystic dysplastic ectopic kidney associated with right severe hydronephrosis due to right ureterocele. Our patient had CRE without fusion, which is extremely rare; this makes our report very interesting since most of the previously reported CRE cases were with fusion.

\section{Case report}

A 5-month-old boy was referred to our hospital due to left ectopic kidney and right hydronephrosis which was diagnosed antenatally. During the patient's hospital stay, a renal ultrasonographic (USG) examination demonstrated: an ureterocele in the urinary bladder, an extremely hypoplastic right kidney with grade 3 to 4 hydronephrosis, a left kidney which was not visualized in its usual localization, and a crossed ectopic kidney in the inferior portion of the right kidney. In abdominal magnetic resonance imaging (MRI) examination, the left kidney was not visualized and grade 3 hydronephrosis in the right kidney with megaureter and ureterocele were detected. Voiding cystoureterograhic examination revealed no vesicoureteric reflux (Fig. 1). Cystoscopy and retrograde pyelography were performed on the patient. Ureterocele of the right collecting duct was diagnosed by cystoscopy. In retrograde pyelography hydronephrosis in the right kidney, dilatation, tortuousity and ureterocele were present in the distal portion of right ureter (Fig. 2). In the dimercaptosuccinic acid (DMSA) study, the left kidney was not visualized, and the right kidney was hypertrophied in which DMSA uptake was minimally decreased and no cortical scar was present. In the patient's abdominal USG examination, the right collecting system was extremely dilated and the dimensions of the ureterocele were measured as $19.5 \times 8.2 \mathrm{~mm}$. In the left ectopic kidney crossed to the right, the pelvic diameter was $8 \mathrm{~mm}$, with dilated proximal ureter $(9.7 \mathrm{~mm})$ and grade 2 to 3 dilation at the left collecting system.

The patient underwent the operation when he was 7-months-old in our clinic. Upon exploration, the left atrophic kidney was found with excessive dilated ureter at the right side, just superior to the bladder. Nephroureterectomy was performed for the left kidney (Fig. 3). The right ureterocele was excised and Cohen type ureteroneocystostomy was performed. The patient was discharged uneventfully on the seventh day postoperatively. Histopathological examination of the specimen was reported as multicystic renal dysplasia. In the abdominal USG performed one year postoperatively, the right kidney and pelvic system were normal. The DMSA and diethylenetriamine pentaacetic acid (DTPA) studies revealed that the right kidney had normal configuration whereas no functional renal tissue was present in the left. Two years after the operation, the patient is followed up without any complication. 


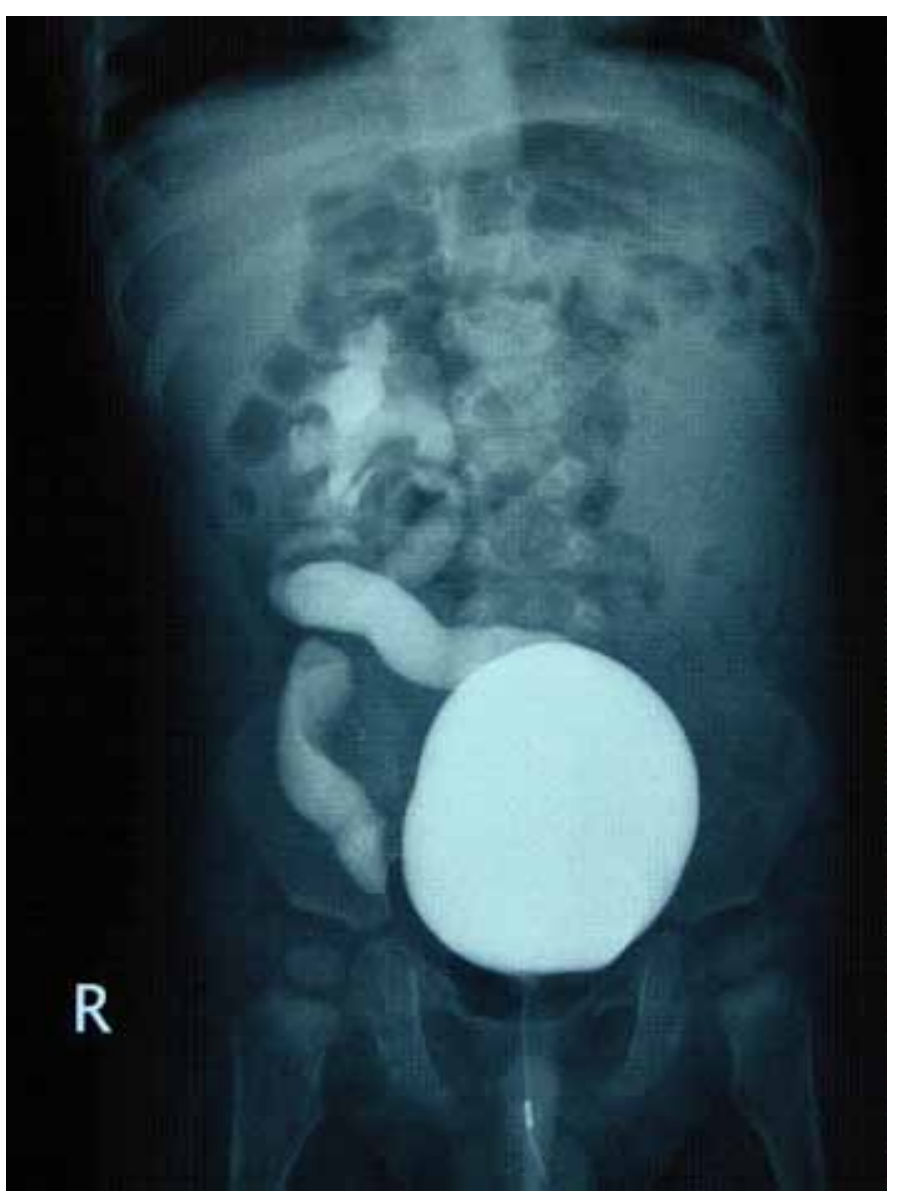

Fig. 1. Left ectopic kidney and bilateral hydroureteronephrosis.

\section{Discussion}

The pathophysiological conditions leading to crossed renal ectopy remain unknown. Faulty development of the ureteric buds, vascular obstruction during the ascent of the kidneys and environmental factors are accused. The most probable cause of crossed renal ectopy was abnormal development of the ureteric bud during the fourth to eighth weeks of gestation. ${ }^{5}$ In $90 \%$ of patients, the crossed kidney was fused with the normal kidney. Crossed renal ectopy anomaly is two times more common in males and the cross from left to right was more common than the cross from right to left. ${ }^{6}$ Nussbaum and colleagues ${ }^{2}$ determined the classical visualisation findings of multicystic dysplastic kidney and crossed renal ectopy necessary for the diagnosis: (1) a multicystic mass of variable size that is contiguous with the lower pole of a hydronephrotic, malrotated kidney; (2) ureteral displacement and/or dilatation; and (3) contralateral absence of the kidney and its renal artery. Consistent with previous reports, our patient was male and the cross was from left to right and all the classical visualisation findings were present, except that the crossed kidney had not been fused with the normal kidney.
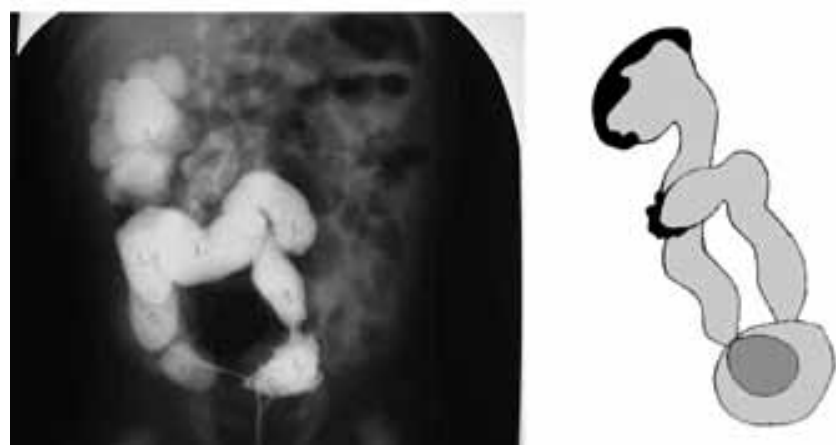

Fig. 2. Right hydroureteronephrosis (labelled 2) and left ectopic kidney and dilated tortuous left ureter (labelled 1) and schematic diagram.

The diagnosis may be possible preoperatively by USG examination, since it allows direct visualization of the orthotopic kidney and ipsilateral caudal mass. For the diagnosis, an intravenous pyelogram, voiding cystourethrography, retrograde pyelography, computed tomography and MRI investigations may also be used. The diagnosis of CRE in our patient was confirmed by cystoscopy and retrograde pyelography. The DMSA and DTPA studies were performed to determine the functional and configurational status of the kidneys.

Unilateral polycystic renal disease, multicystic renal dysplasia and renal aplasia are all synonymous with renal dysplasia, which is a rare pathological condition. ${ }^{7}$ The association of crossed renal ectopy with renal dysplasia is very rare and a few of these cases were reported. ${ }^{8,9}$ In our patient, histopathological examination was reported as multicystic renal dysplasia. In most cases with multicystic dysplastic kidney, no functional parenchyma is present. Intravenous urography and isotope renography show the function of the orthotopic kidney, but also the lack of function in the ipsilateral lower mass and contralateral flank. Consistent with this finding, the DMSA and DTPA studies demonstrate no function in an ectopic kidney.

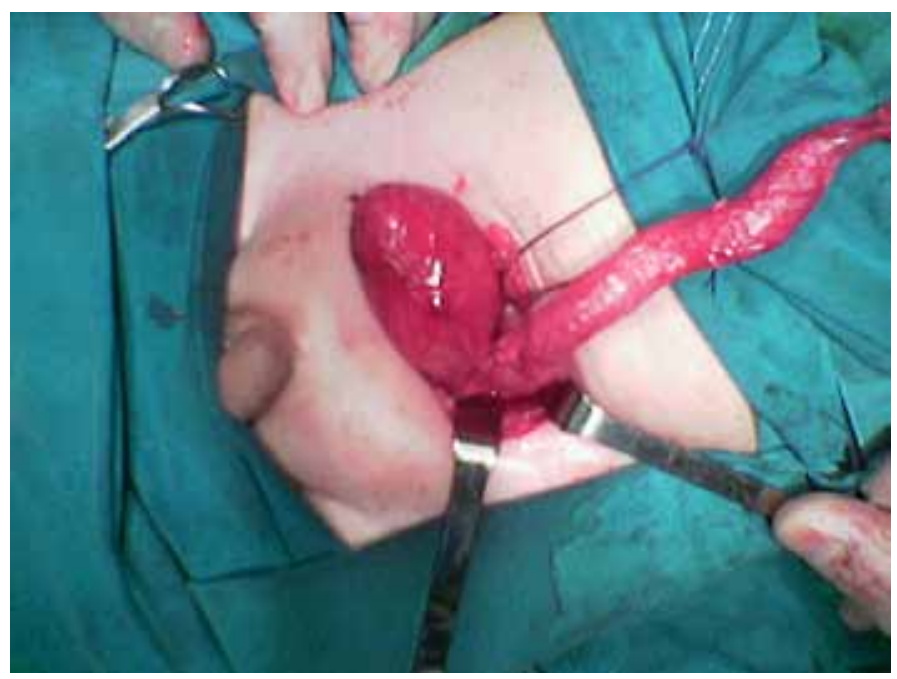

Fig. 3. Atrophic left kidney and dilated, tortuous ureter (intraoperative view). 
Although most of the CRE cases were asymptomatic and diagnosed during autopsy studies, ${ }^{4,10}$ the prenatal diagnosis of this patient was performed due to grade 4 hydroureteronephrosis and he was evaluated postnatally without delay.

\section{Conclusion}

In the current English language literature, there is only one case of multicystic dysplastic kidney associated with CRE and ureterocele. ${ }^{11}$ Our patient is the second reported case with this association. In the first reported case, the nonectopic kidney was normal and no surgical intervention was performed for the crossed ectopic kidney. Contrary to this first reported case, we performed nephroureterectomy for the ectopic kidney, excision of the ureterocele and Cohen type ureteric reimplantation for the right kidney due to grade 4 hydronephrosis. Our case was the first reported patient who underwent the surgical intervention for CRE.

"Afyon Kocatepe University Faculty of Medicine Department of Pediatric Surgery, Afyon Kocatepe Universitesi Tip Fakültesi, Turkey; †'zmir Behçet Uz Children Hospital Department of Radiology,

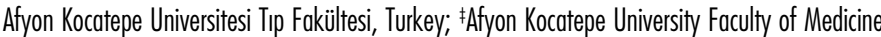
Department of Pediatrics, Afyon Kocatepe Universitesi Tip Fakültesi, Turkey; ${ }^{*}$ Gulhane Military Medical Academy, Department of Pediatric Surgery, Afyon Kocatepe Universitesi Tip Fakültesi, Turkey

\section{References}

1. Mouriquand P. Renal Fusions and Ectopia. In: JA 0'Neill, MI Rowe, JL Grosfeld, EW Fonkalsrud, AG Coran, eds. 5th Edition. Pediatric Surgery. Mosby: St Louis, 1998:1583-8.

2. Nussbaum AR, Hartman DS, Whitley N, et al. Multicystic dysplasia and crossed renal ectopia. AJR Am J Roentgenol 1987;149:407-10.

3. Mouriquand P. Renal Fusions and Ectopia. In: JA O'Neill, MI Rowe, JL Grosfeld, EW Fonkalsrud, AG Coran, eds. 5th Edition. Pediatric Surgery. Mosby: St Louis, 1998:407-10.

4. Sood R, Truong MX, Rossleigh MA, et al. Renal scintigraphy unraveled the diagnostic dilemma of antenatal hydronephrotic solitary kidney-crossed renal ectopia. Clin Nucl Med 2005; 30:621-2.

5. Boyan N, Kubat H, Uzum A. Crossed renal ectopia with fusion: report of two patients. Clin Anat 2007:20:699-702

6. Lee HP. Crossed unfused renal ectopia with tumor. J Urol 1949;61:333

7. Daniel WW, Datnow B. Crossed fused renal ectopia with renal dysplasia. AJR Am J Roentgenol 1977; 128:845-6.

8. Aguilera Tubet C, Del Valle Schaan Jl, Martín García B, et al. Renal cell carcinoma in crossed fused renal ectopia. Actas Urol Esp 2005;29:993-6.

9. Romero FR, Chan DY, Muntener M, et al. Laparoscopic heminephrectomy for renal cell carcinoma in cross-fused ectopic kidney. Urology 2007;69:779.e1 1-3.

10. Guarino $\mathrm{N}$, Tadini $\mathrm{B}$, Camardi $\mathrm{P}$, et al. The incidence of associated urological abnormalities in children with renal ectopia. J Urol 2004;172(4 Pt 2):1757-9; discussion 1759.

11. Kiddoo DA, Bellah RD, Carr MC. Cross-fused ectopic multicystic dysplastic kidney with associated ureterocele. Urology 2005;66:432.

Correspondence: Dr. Adnan Narcı, Afyon Kocatepe Universitesi Tip Fakültesi Cocuk Cerrahisi AD, 03200, Afyonkarahisar/Turkey, adnannarci@yahoo.com

Competing interests: None declared.

This paper has been peer-reviewed. 